\title{
UPDATE ARTICLE
}

\section{Autism spectrum disorders: an overview on diagnosis and treatment}

\author{
Helena Brentani, ${ }^{1,2}$ Cristiane Silvestre de Paula, ${ }^{3,4}$ Daniela Bordini, ${ }^{3}$ Deborah Rolim, ${ }^{2}$ Fabio Sato, ${ }^{2}$ \\ Joana Portolese, ${ }^{2}$ Maria Clara Pacifico, ${ }^{2}$ James T. McCracken ${ }^{5}$ \\ ${ }^{1}$ Department of Psychiatry, School of Medicine, Universidade de São Paulo (USP), São Paulo, SP, Brazil. ${ }^{2}$ Autism Spectrum Program, \\ Institute of Psychiatry, School of Medicine, USP, São Paulo, SP, Brazil. ${ }^{3}$ Child and Adolescent Psychiatry Unit, Department of Psychiatry, \\ Universidade Federal de São Paulo (UNIFESP), São Paulo, SP, Brazil. ${ }^{4}$ Graduate Program in Development Disorders, Health and Biological \\ Science Center, Universidade Presbiteriana Mackenzie, São Paulo, SP, Brazil. ${ }^{5}$ Department of Psychiatry and Biobehavioral Sciences, \\ University of California, Los Angeles, CA, USA.
}

\begin{abstract}
Pervasive developmental disorders are now commonly referred to as autism spectrum disorders (ASDs). ASDs present with a range of severity and impairments, and often are a cause of severe disability, representing a major public health concern. The diagnostic criteria require delays or abnormal functioning in social interaction, language, and/or imaginative play within the first 3 years of life, resulting in a deviation from the developmental pattern expected for the age. Because establishing a diagnosis of ASD is possible as early as 18-24 months of age, clinicians should strive to identify and begin intervention in children with ASD as soon as signs are manifest. Increasing efforts are underway to make ASD screening universal in pediatric healthcare. Given the crucial importance of early identification and multiple modalities of treatment for ASD, this review will summarize the diagnostic criteria, key areas for assessment by clinicians, specific scales and instruments for assessment, and discussion of evidence-based treatment programs and the role of specific drug therapies for symptom management.
\end{abstract}

Keywords: Autistic disorder; pervasive development disorders; diagnosis, treatment

\section{Introduction}

According to the American Psychiatric Association's DSM-IV, ${ }^{1}$ the category of pervasive developmental disorders (PDDs) includes autistic disorder, Asperger's disorder, pervasive developmental disorder not otherwise specified (PDD-NOS), childhood disintegrative disorder (CDD, Heller's syndrome), and Rett's disorder. This group of disorders is characterized by a shared spectrum of qualitative impairments in social interaction, associated with varying degrees of deficits in communication and marked repetitive behaviors and restricted interests. PDDs are now commonly referred to as autism spectrum disorders (ASDs). Diagnosing ASD requires a comprehensive, systematic, and structured approach. Besides meeting the goal of identifying the disorder, the diagnostic assessment provides important information on the child's relative strengths and weaknesses, identifies which maladaptive behavior and comorbid difficulties are present, clarifies the impact of the child's condition on the family, and benchmarks the developmental skills of the patient. In this way, the assessment should establish a roadmap for treatment by identifying the capabilities and challenges for the child and providing useful information

Correspondence: Helena Paula Brentani, Child and Adolescent Psychiatry, Universidade de São Paulo (USP), Rua Dr. Ovídio Pires Campos, s/nº, CEP 05403-010, São Paulo, SP, Brazil.

E-mail: helena.brentani@gmail.com on the needs and skills that must be addressed by intervention. Because establishing a reliable diagnosis of ASD is possible as early as $18-24$ months of age, clinicians should strive to identify and begin intervention in children with ASD as soon as signs are manifest. ${ }^{2}$

\section{Epidemiology}

The pioneering epidemiologic study in autism was conducted by Victor Lotter in the 1960s in England. ${ }^{3}$ Studies conducted after the 1990s detected estimates of autistic disorder prevalence between 10 and 16 per 10,000 inhabitants, while the current estimated rates of PDD are approximately $60 / 10,000,4,5$ representing a nearly 10-fold increase compared to earlier reports in the literature. Epidemiologic surveys from around the world have found individuals with ASD in all studied regions, and with roughly similar prevalence rates. ${ }^{6}$ PDDNOS is routinely found to be the most frequent diagnosis $(3 / 1,000)$, followed by autistic disorder $(2 / 1,000)$, while Asperger's disorder is significantly less common (6/ 10,000). Rett's disorder and CDD are very rare (2/ $100,000){ }^{7}$ A recent study by the U.S. Centers for Disease Control Prevention (CDC), using a surveillance system, found an overall prevalence of approximately $1 \%$ for ASD in several regions of the United States. ${ }^{8}$

Only four studies presenting epidemiological data from Latin American countries have been published. ${ }^{6}$ In Brazil, 
a pilot study of the prevalence of ASD was conducted at a local administrative area in the state of São Paulo. The study included 1,470 children aged 7 to 12 years old and was based on a combination of standardized instruments and clinical assessments using the DSM-IV criteria. The survey estimated a prevalence of ASD of $0.3 \%$, and some hypotheses were raised to explain this low frequency, the main one being the small sample size. ${ }^{9}$ Taken together, the combined prevalence of ASDs makes them one of the most frequent neurodevelopmental disorders, representing a major public health concern.

\section{Diagnostic criteria}

The current specific criteria for ASD diagnoses are drawn from three domains:

i) Impaired social interaction, as shown by: a) marked impairment in the use of non-verbal communicative behaviors (such as eye-to-eye gaze, facial expression, body postures); b) failure to develop age-appropriate peer relationships; c) a lack of spontaneous sharing of affect and interests with others; and d) lack of social or emotional reciprocity (limited interest in or awareness of others' reactions, interests, or feelings).

ii) Qualitative impairments in communication skills, as shown by: a) delays in, or lack of, language acquisition (absence or reduced frequency of early language development as babbling and playing with sounds, and later, absence of phrase speech); b) inability to initiate or maintain a conversation; c) stereotyped and repetitive use of language or idiosyncratic language (echolalia, oddly formal speech, neologisms); and d) lack of development of age appropriate pretend play or social imitative play.

iii) Presence of restricted and repetitive patterns of behavior, interests and activities, as shown by: a) pronounced preoccupation with one or more unusual and restricted interests; b) inflexible adherence to specific routines or rituals; c) motor stereotypies (hand flapping, finger flicking, pacing, and jumping); and d) preoccupations with parts of objects.

In order to meet full criteria for autistic disorder, the individual must have evidence of a total of six or more items from domains i), ii), and iii), with at least two items from i), and one each from ii) and iii). Individuals with Asperger's disorder by definition are considered to have no clinically significant language delays, and must manifest two or more criteria from i) and at least one criterion from repetitive, restricted interests (iii). The diagnosis of PDD-NOS is considered a form of subthreshold autism or autism with atypical features in individuals with severe and pervasive social communication impairments and/or impairing restricted interests and repetitive behaviors, but where the required criteria for autistic disorder or Asperger's disorder is not met. Rett's disorder and CDD have distinct developmental and behavioral profiles (severe deceleration of motor skills and head growth between 5 to 30 months for Rett's disorder and marked, pervasive developmental and behavioral deterioration after apparently normal development for at least 2 years in CDD).

The diagnostic criteria require the appreciation of delays or abnormal functioning in social interaction, language, and/or imaginative play within the first 3 years of life, resulting in a deviation from the developmental pattern expected for their age. ${ }^{10}$ Hence, a priority is to identify early signs of ASD and initiate interventions as soon as possible, as it is widely recognized that early intervention results in a better prognosis. ${ }^{11}$ Longitudinal studies of infants at high-risk for autism by virtue of having an older affected sibling, and retrospective examinations of first-birthday videos in children later diagnosed with autism confirm that, in some children, the delays and deviations of ASD are identifiable between 6 and 12 months of age, ${ }^{12}$ becoming more stable after 18 months of age. ${ }^{13}$ Autism diagnoses at 24 months of age have been found to be stable over follow-up periods of several years. Although the first symptoms described in the literature are related to social communication, these longitudinal studies have shown that infants with other more non-specific signs not related to sociability can be identified even earlier. These signs include irritability, lack or excess of responsiveness, changes in activity level, and deficits in gross motor development. ${ }^{14}$ Retrospective reports from the CDC autism surveillance network noted that more than $50 \%$ of parents of children with autism had voiced concerns about their child's development or behavior in the first 12 months of life, and that $80 \%$ had identified concerns about language development by 36 months. ${ }^{15}$ Clinicians are strongly encouraged to take note of such early concerns and possible deviations and consider intervention, rather than to suggest prolonged monitoring.

The DSM-5 has just been officially released and in its most recent text renames the category as ASD, with significant changes in the diagnostic classification and criteria for the PDDs as compared to the DSM-IV according to a recent editorial on the subject. ${ }^{16}$ The main changes in the diagnosis criteria are presented in Table 1.

\section{Screening evaluations}

In the United States, pediatricians are recommended to perform routine specific ASD screening at 18 and again at 24 months. ${ }^{17}$ The approach to screening assessments for suspected ASD includes the following:

ASD specific symptom screening for DSM criteria in primary care or general medical settings (Level 1). These screening approaches can be performed using completion of well validated checklists, such as the Developmental Behavioral Checklist-Parent (DBC$\mathrm{P}),{ }^{18}$ the Modified Children's Autism Test (MCHAT), ${ }^{19}$ the Autism Behavior Checklist $(\mathrm{ABC}),{ }^{20}$ or the Autism Screening Questionnaire (ASQ). ${ }^{21}$ For those children identified as high-risk for ASD by virtue of positive initial screening, more in-depth assessments should then be pursued (Level 2). These include: 
Table 1 Changes in the diagnostic criteria for the PDDs in the DSM-5 (adapted from Ozonoff ${ }^{16}$ )

1) The category of pervasive developmental disorders will be replaced with ASD.

2) Three symptom domains will be collapsed into two domains: social communication (comprising elements of impaired social interaction and impaired communication), and restricted interests and repetitive behaviors.

3) Creation of a single diagnosis (ASD) with the elimination of Asperger's disorder.

4) Rett's disorder will be eliminated.

5) Number of symptoms condensed from 12 to seven merging criteria that were overlapping and eliminating symptoms that are not specific to ASD (e.g., delayed development of language).

6) Inclusion of a new symptom of unusual sensory sensitivity within the restricted interests and repetitive behaviors domain.

7) Addition of a severity criterion that will clarify the nature of the spectrum, as well as its variability, such as intensity and duration of symptoms, amount of impairment associated.

8) Establishment of a new social communication disorder category to provide diagnostic coverage to individuals who only have social communication problems but do not display the repetitive and stereotyped behaviors of ASD.

$\mathrm{ASD}$ = autism spectrum disorder; PDD = pervasive developmental disorder.

1) The Childhood Autism Rating Scale (CARS). ${ }^{22}$

2) Determination of social abilities and adaptive skills. The Social Responsiveness Scale (SRS), ${ }^{23}$ completed by a parent, can provide information relating to social abilities. The Vineland Adaptive Behavior Scales (Vineland-II, 2nd edition) ${ }^{24}$ can be administered by a clinician or completed by parents to assess adaptive skills.

3) Screening for maladaptive behaviors and comorbid problems (e.g., hyperactivity, irritability, aggression, temper outbursts, self-injury, mood, anxiety symptoms) can be assessed by means of parent or caregiver completion of the Aberrant Behavior ChecklistCommunity Version (ABC-CV). ${ }^{25}$

4) Screening for medical comorbidities (history of elimination disorders, seizures, gastrointestinal problems, growth abnormalities). The role of medical testing in the assessment of ASD is increasing, although full consensus is lacking as to what tests are considered universally appropriate. Examples include possible electroencephalogram testing, given that the rate of comorbid epilepsy in ASD varies between 15-30\%. When epilepsy is present, a neurologist assessment should be indicated.

5) Screening for indicators of genetic syndromes associated with autism (family history, dysmorphic features, head size, café au lait spots, inherited metabolic disorders). Currently, it is recommended that if the patient presents with mental retardation, minor physical anomalies, syndromic features or family history, genetic evaluation should be suggested. The indications for molecular genetic testing are rapidly expanding, with many specialists now recommending comparative genomic hybridization testing or wholeexome sequencing for individuals with a confirmed diagnosis of ASD. ${ }^{26}$

\section{Diagnostic instruments}

The accepted gold standard diagnostic assessments for an ASD diagnosis are the Autism Diagnostic Observation Schedule (ADOS) ${ }^{27}$ and the Autism Diagnostic Interview, Revised $(A D I-R)^{28}$ because of their extensive detail of behavioral and developmental characterization, and their reliability among raters trained in their administration. The original ADI was established for research and was used to evaluate the behavior of individuals older than 5 years, whose chronological and mental age was at least 2 years, based on diagnostic criteria proposed by the ICD-10 and DSM-IV. Subsequently, the ADI-R was revised and modified to be appropriate for children from mental ages 18 months through adulthood.

The ADOS is a semi-structured clinician-administered interview that assesses a wide range of ASD-specific characteristics including verbal and non-verbal communication, reciprocal interaction, and conversational ability. It requires approximately 45 minutes for administration. There are separate ADOS modules based on age, language, and developmental level, such as the ADOS$\mathrm{T}$ for toddlers, and Modules 1-4 that are validated for children, adolescents, and adults. It is important to note that both ADI-R and ADOS need specialized training for administration, but they can be administered by a wide range of specialists. The $\mathrm{ADI}-\mathrm{R}$ has already been translated and validated in $\mathrm{Brazil}^{29}$ and there is a Brazilian version of ADOS (personal communication by Maria Clara Pacifico, Cristiane S de Paula, and Guiomar Oliveira, 2012).

\section{Complementary evaluations}

\section{Assessment of developmental level of intellectual abilities}

Cognitive dysfunction is nearly ubiquitous in ASD and important in determining overall functional capacity, although the severity and breadth of cognitive deficits vary widely in individuals on the spectrum. ${ }^{30}$ Additionally, it is important for the differential diagnosis or co-occurring diagnosis with mental retardation. In cases of patients with autism, approximately $60-70 \%$ have some level of intellectual disability (mental retardation), whereas most individuals with Asperger's disorder and PDD-NOS test in the normal range of intelligence, albeit with frequent, more compartmentalized areas of deficits. ${ }^{31}$ Conversely, around $10 \%$ of individuals with ASD have remarkable skills for their age ("savants"), often representing highly specialized and restricted skills not in keeping with their impaired global functioning. ${ }^{10}$ Even among those ASD individuals deemed to be high-functioning, by virtue of scoring within the normal range of full scale IQ measures, neuropsychological testing routinely reveals cognitive dysfunction, particularly on executive functions and social 
cognition, such as set-shifting, planning, inhibitory control, and theory of mind deficits. ${ }^{32}$

\section{Assessment of developmental level of language}

A speech therapist evaluation is important since approximately $20-30 \%$ of ASD individuals are nonverbal and between 20 and $25 \%$ of them present a developmental history of marked regression in terms of loss of previously acquired language. ${ }^{33}$ Some pre-verbal skills, such as joint attention, response to speech, gestures, imitation, and symbolic play, are considered strong predictors for early verbal communication. ${ }^{34,35}$ Identifying impairments of these skills is important for intervention as these represent foundational skills for language acquisition. Delays are also seen in the transition from the use of isolated to combined words. A study from Paul et al. ${ }^{36}$ showed that even children with ASD who have achieved productive use of isolated words and have a repertoire in their expressive vocabulary of 100 words at 28 months are still at high risk to not progress to sentence production with more than one word. In contrast, 28-month-old children with typical development and who have the same size of vocabulary repertoire are uniformly able to combine words into phrases. Although many children with ASD present significant progress in language in the period from 24 to 48 months, with vocabulary expansion and scores within the mental age showed by appropriate tests of receptive and expressive abilities, their overall communication ability remains impaired. While the lack of acquisition of phrase speech by age 5 years has often been cited as predicting severely limited lifetime language development, recently descriptions of later emergence of language have been described in a number of cases. ${ }^{37}$ When children with ASD begin to talk, some distinctive features in the language form and content appear, such as echolalia. Echolalia is the repetition of other's speech and it can be immediate or delayed, partial or total. Echolalia was initially seen as an undesirable and dysfunctional behavior, however, current studies ${ }^{38}$ suggest children use it as a strategy to communicate. As language skills improve, echolalia tends to disappear. ${ }^{38}$ The pronoun inversion is another common behavior in the speech of children with ASD and seems to be related to the nature of deictic pronouns, which can be confusing for younger children of the spectrum. In deictic pairs like I/you, the reference changes depending on the viewpoint of the speaker. Children with ASD have particular difficulty with this concept due to the literalness of language and lack of flexibility. ${ }^{39}$ Even when the subject produces words and grammatically correct sentences, their speech reflects fundamental flaws of understanding and expression of attitudes and intentions. In general, children with ASD have vocabulary with little information. Many start talking only naming specific objects or figures. ${ }^{40}$

Several authors have attempted to define specific profiles of the nature of language impairments in individuals with autism, Asperger's disorder, semantic-pragmatic syndrome, and specific language impairment. ${ }^{41-45}$ However, because many characteristics are found to be overlapping and/or are interrelated, such differences are often found to be subtle and highly individualized making a speech evaluation necessary. In Table 2, characteristics of each disorders are summarized. To sum up, it can be concluded that children with ASD have more difficulties in linguistic structure, interests, and social use of language. Individuals with Asperger's syndrome by definition display fewer problems with linguistic structure, but do manifest pragmatic difficulties, and deficits in the effective social use of language. Children with semantic-pragmatic disorder, in contrast, have difficulties in understanding linguistic structures and social interest. ${ }^{46-48}$

\section{Treatment}

Over the past two decades, with the increased number of infants and toddlers diagnosed with ASD, there is a need for effective and appropriate interventions for the children

Table 2 Differential diagnosis of language disorders

\begin{tabular}{|c|c|}
\hline Autism & $\begin{array}{l}\text { - Atypical verbal language, such as failures in the use of gestures, facial expressions, and gaze } \\
\text { exchange } \\
\text { - No verbalization or atypical forms, content and use of language (echolalia, pronoun reversal) } \\
\text { - Impairment in receptive language } \\
\text { - Commitment in symbolic play } \\
\text { - Restricted interests }\end{array}$ \\
\hline Asperger's syndrome & $\begin{array}{l}\text { - Absence of delayed speech } \\
\text { - Absence of cognitive impairment } \\
\text { - Ability to memorize large amounts of information } \\
\text { - Restricted interests } \\
\text { - Impairment in reciprocal social interaction }\end{array}$ \\
\hline Specific language impairment & $\begin{array}{l}\text { - Delay in language development not overcome until } 5 \text { years old } \\
\text { - Difficulty with the structural aspects of language } \\
\text { - High occurrence of deviant phonological processes (not observed in the normal process of language } \\
\text { acquisition) } \\
\text { - Overuse of gestures and vocalizations } \\
\text { - Short speeches, often with inadequate cohesion and coherence }\end{array}$ \\
\hline Pragmatic language impairment & $\begin{array}{l}\text { - Inability in understanding and maintaining conversation } \\
\text { - Failures of content and form in sentence construction } \\
\text { - Inappropriate social responses } \\
\text { - Tangential speech }\end{array}$ \\
\hline
\end{tabular}


and their families that address core impairments and co-occurring conditions. ${ }^{49}$ The National Research Council (NRC) $)^{50}$ conducted a systematic review of research on interventions for children with ASD from birth through 8 years of age. Few well-controlled studies were conducted to test the effectiveness of specific modalities of intervention. Priority for instruction should be in a) functional, spontaneous communication, b) social instruction across settings, c) play skills, with a focus on peer interaction, d) new skill maintenance and generalization in natural contexts, and e) functional assessment and positive behavior support to address problem behaviors. Intervention effects should be evaluated regularly at 3-6 months intervals, focusing on: a) social skills, b) communication skills, c) adaptive skills, d) organizational skills. Table 3 shows the essential characteristics of effective interventions for children with ASD determined by the NRC. Lack of significant progress in any domain over a 3-6 month period should prompt modification of treatment approach or intensity.

\section{Treatment approaches}

\section{Parent training}

Parental and family involvement is considered an essential element of intervention programs for children with autism. ${ }^{50}$ The basic assumption of behavioral parent training is that child behavior is learned and maintained through contingencies within the family context and that parents can be taught to change these contingencies in order to promote and reinforce appropriate behavior. ${ }^{51}$

Evidence involving young children supports the recommendation of parent training as an effective method for increasing social skills. However, the manner in which parents are incorporated into the intervention process is important, as well as individualizing the parent education program to consider different family needs and circumstances; not every parent benefits from traditional behavioral parent education programs. Parent education appears to work best with highly motivated and wellfunctioning adults who are not coping with additional psychological or life stressors, which interferes with their acquisition and implementation of positive parenting strategies. ${ }^{52}$ The literature documents the effectiveness of parent education programs and the lack of maintenance of behavioral gains when parents do not participate in their children's interventions programs. ${ }^{53-55}$

\section{Applied behavioral analysis}

Applied behavior analysis (ABA) is the science of behavior modification in which procedures derived from the principles of operant learning are applied to improve socially adaptive behavior and acquisition of new skills through intensive practice and targeted reinforcement. ${ }^{56}$ ABA utilizes a process that begins with the development of treatment plans outlining the purpose and function of behavioral excesses or deficits, selection of appropriate techniques, and continual evaluation and modification of the treatment through systematic data collection. Functional behavioral assessments are a related set of assessment strategies that provide information on the variables associated with a specific behavior. ${ }^{57}$ The operant learning techniques used in ABA intervention for ASDs children are:

- Positive reinforcement: use of praise, snack, food, toys to increase desired behaviors;

- Shaping: rewarding approximations or components of a desired behavior until target behavior is exhibited;

- Fading: reducing prompts to increase independence;

- Extinction: removal of reinforcement maintaining a problem behavior;

- Punishment: applying undesired stimulus to reduce problem behaviors;

- Differential reinforcement: reinforcing a socially acceptable alternate or absence of a behavior.

Intervention programs based on $A B A$ are currently viewed as the first-line treatment for ASD in early childhood. ${ }^{58}$ Both the UCLA/Lovaas model and the Early Start Denver Model (ESDM), which are comprehensive early intervention programs built on a framework of $A B A$, have high quality research reports documenting their efficacy, ${ }^{59}$ especially for improving cognitive performance, language skills, and adaptive behavior. However, in the seminal study evaluating the benefits of ESDM, even after 2 years of intensive intervention (more than 20 hours/week), all children in the active treatment group still met criteria for ASD, documenting the challenge of ameliorating social deficits. ${ }^{60}$ The Early Intensive Behavioral Intervention (EIBI) is a behavioral strategy utilized in the Lovaas ${ }^{61}$ study and is the ABA model with the strongest empirical support to date. ${ }^{57}$ EIBI utilizes operant learning approaches to reduce problem behaviors and discrete trial training to develop new skills, such as attention, imitation, receptive/expressive speech and life skills. Core features of the EIBI are:

1) Focus on early development (children younger than 5 years);

2) Intensity (one-on-one and small group instruction, 2040 hours/week);

3) Adult-directed methods;

4) Systematic approach (breaking down skills into basic components);

Table 3 Essential characteristics of effective interventions for children with autism spectrum disorder

1) Start intervention programs as earlier as possible.

2) Intensive treatment, 5 days a week for a minimum of 5 hours per day.

3) Use of repeated planned teaching opportunities that are structured over brief periods of time.

4) Sufficient individualized adult attention on a daily basis.

5) Inclusion of a family component, including parent training.

6) Mechanisms for ongoing assessment with corresponding adjustments in programming. 
5) Comprehensive nature (e.g., the targets include communication, socialization, adaptive behaviors, problem behaviors).

Treatment and Education of Autistic and Related Communication-Handicapped Children (TEACCH)

TEACCH is a classroom based, clinical service and professional training program, developed at the University of North Carolina, at Chapel Hill, and started in 1972 by Eric Schopler. ${ }^{62}$ This program has been incorporated widely into North American educational settings and has contributed significantly to the evidence base of autism interventions. The TEACCH approach is called structured teaching because it is based on evidence and observation that individuals with autism share a pattern of behaviors, such as the ways individuals think, eat, dress, understand their world, and communicate. The essential mechanisms of structured teaching consist of organizing the environment and activities in ways that can be understood by the individuals; using individuals' relative strengths in visual skills and interest in visual details to supplement relatively weaker skills; using individuals' special interests to engage them in learning; and supporting self-initiated use of meaningful communication.

\section{Cognitive-behavioral therapy (CBT)}

A growing number of reports have begun to provide moderate evidence for the efficacy of CBT approaches for school-age and young adolescents with ASD. ${ }^{55,63}$ Improvements in anxiety, self-help, and daily living skills have been reported, with $78 \%$ of $7-11$ year-olds in the CBT-treated group rated as positive responders in one trial. ${ }^{55}$ Such findings encourage the consideration of modified CBT approaches to address anxiety in highfunctioning children with ASD, which is important given that as many as $30-40 \%$ of children with ASD report high levels of anxiety-related symptoms.

\section{Pharmacological treatment for target symptoms}

Pharmacological treatment in ASD is widely employed as an adjunctive treatment approach in the majority of individuals with ASD across the lifespan. ${ }^{64,65}$ The bestestablished goals of pharmacotherapy are to control often associated target symptoms, such as insomnia, hyperactivity, impulsiveness, irritability, auto and heteroaggressiveness, inattention, anxiety, depression, obsessive symptoms, tantrums, anger attempts, repetitive behaviors or rituals. Numerous studies have reported an increased prevalence of psychiatric comorbidities in this population. ${ }^{66,67}$ Simonoff et al. found that $70 \%$ of subjects with ASD had at least one comorbid psychiatric disorder and $41 \%$ had two or more diseases. Comorbid symptoms often compound the functional impairments in patients with ASD and may limit the effectiveness of nonpharmacological interventions. At present, there are no available drugs to treat the core social and communication deficits of autism, although this is a subject of intensive research efforts with agents such as arbaclofen, oxytocin, and mGluR5 antagonists as examples of potentially disorder-modifying treatments under study.

Despite varying levels of empirical support for some targeted medication choices, drug treatment of children and adults with ASD is common clinical practice. Around 45$75 \%$ of children with ASD are medicated with psychotropic drugs ${ }^{64,65}$ Most commonly prescribed medicines, in order of frequency, are antidepressants, antipsychotics, anticonvulsants, and stimulants, many of them without definitive studies guiding their usage. It should be noted that most psychotropic use in ASD is off-label, as there are currently just two medications (risperidone and aripiprazole) approved by the Food and Drug Administration (FDA), and only for the treatment of associated behaviors. ${ }^{68}$

Based on parental reports, the most difficult behaviors of children with ASD are low frustration threshold, distractibility, irritability, inattention, hyperactivity, compulsive repetition, isolation, mood instability, and stereotyped hand movements. ${ }^{69}$

\section{Aggressive behavior and irritability}

More than $50 \%$ of children with autism show selfaggression, and as many as $14.6 \%$ practice severely intense self-aggression that may lead to hospitalization, institutionalization, removal from less restrictive school settings, and a worse prognosis. ${ }^{70,71}$ The causes of irritability and aggression are multifactorial: comprehension difficulties, decreased ability to communicate and express their needs and desires, reduced confrontation skills, conflict with colleagues and authority figures, psychosocial dysfunction, undiagnosed pain, mood and anxiety disorders. ${ }^{70}$ The first step to address the aggressive behavior is to identify the cause and then find the most appropriate therapeutic approach (behavioral management and/or medication). First- and second-generation antipsychotics have shown moderate to large benefits in controlling aggressive symptoms in autism. $^{70}$ In 2002, the Research Units in Pediatric Psychopharmacology (RUPP) Autism Network reported on a multicenter clinical trial that evaluated the efficacy of short- and long-term risperidone in children and adolescents aged 5-17 years with autism accompanied by with tantrums, aggression, self-injurious behavior. ${ }^{72}$ The results showed that short-term risperidone treatment was markedly superior to placebo in these cases (positive responders: 75 vs. $12 \%$, respectively), reducing maladaptive behaviors broadly, including decreased irritability (aggression, agitation, severe temper outbursts), decreased hyperactivity, and reductions in stereotypies. Risperidone treatment was well tolerated for up to 6 months; side effects found to be common in earlier studies with haloperidol were comparatively lower with risperidone. Drowsiness and weight gain were the most commonly reported side effects. Most of seven randomized clinical trials with risperidone, two re-analyses and two association studies demonstrated some efficacy regarding analyzed parameters (irritability, aggressiveness, hyperactivity, general functioning $)^{73-81}$ 
with risperidone. Effective doses were low, averaging $2 \mathrm{mg}$ per day. There was no evidence of tolerance or need to increase the dose in subjects followed for up to 6 months of treatment. Recently, the FDA approved aripiprazole for treatment of irritability in children with autism aged 6 to 17 years with severe irritability. Two double-blind, placebocontrolled clinical trials showed that aripiprazole is effective in treating irritability, hyperactivity, and stereotypies in ASD. ${ }^{82-84}$ In addition, aripiprazole has been reported to be well tolerated in dose ranges of $5-15 \mathrm{mg}$ per day, and is associated with lower mean weight gain compared to many other atypical antipsychotics, as measured during the initial 8 weeks of exposure.

Two randomized clinical trials with few children with ASD using haloperidol showed significant positive effects on behavioral symptoms and global functioning. ${ }^{85,86}$ Using scales of autistic symptoms (ABC), Miral et al. ${ }^{87}$ compared the effects of haloperidol and risperidone treatment with the latter being superior only for the total score. These studies suggest a positive role of haloperidol for the treatment of children with severe or refractory autism. ${ }^{73}$ However, extrapyramidal side effects are common with haloperidol, increasing concern over possible long-term effects of exposure in this population.

Other atypical antipsychotics need further clinical evaluation. Olanzapine has not been studied in randomized placebo-controlled trials in children or adults with ASD. However, some case studies ${ }^{88,89}$ and an open trial $^{90}$ reported positive results. Additionally, a randomized trial with a parallel control group treated with haloperido ${ }^{91}$ reported positive results, although patients had significant weight gain. The prolonged use of olanzapine may induce significant metabolic changes, which hampers its use in children and adolescents with ASD. ${ }^{92}$ Ziprasidone was studied in one open study (2007) that included 12 adolescents with ASD treated with ziprasidone, with doses ranging from 20 to $160 \mathrm{mg} / \mathrm{day}$. A $75 \%$ response rate to treatment was observed according to the parameters of the Clinical Global Impression (CGI). In addition, there was an improvement in the $A B C$ subscales of irritability and hyperactivity. Ziprasidone did not cause weight gain, but a regular increase in the QTc interval of 14.7 milliseconds in the sample was described. ${ }^{93}$ Another open clinical study ${ }^{94}$ and a retrospective review of clinical records ${ }^{95}$ showed promising results for ziprasidone in patients with ASD. Double blind, placebo-controlled studies are needed to validate the use of ziprasidone in this population. An open trial with a small number of individuals concluded that quetiapine was poorly tolerated and ineffective in ASD. ${ }^{96}$ There is no evidence to substantiate clozapine usage taking into account the presence of potentially serious side effects such as seizures and neutropenia, with only case reports available. ${ }^{97}$

\section{Repetitive behavior}

Most studies of selective serotonin reuptake inhibitors (SSRIs) have shown lack of clinically significant efficacy in the treatment of repetitive behaviors and restricted interests of autistic spectrum patients. ${ }^{98,99}$ Only one methodologically relevant study showed some positive results of a SSRI (fluoxetine) compared to placebo, ${ }^{100}$ but improvements were small. In the largest study of the treatment of repetitive behaviors in ASD comparing citalopram to placebo, no benefits were found for citalopram, and side effects, such as hyperactivity, insomnia, and behavioral deterioration, were common. ${ }^{101}$ Interestingly, in contrast to studies in children, two, rigorous, placebo-controlled studies showed benefits for fluvoxamine and fluoxetine on measures of repetitive behaviors for adults, ${ }^{102,103}$ however again the benefits in the fluoxetine study were small relative to placebo. Taken together, there is limited evidence to support the use of SSRIs as treatment for repetitive behaviors in ASD. No large-scale controlled trials have examined their effects for the treatment of anxiety or depressive symptoms in individuals with ASD.

\section{Hyperactivity, impulsivity, and inattention}

Symptoms of attention deficit hyperactivity disorder (ADHD) are very common in individuals with ASD, affecting between $28-74 \%$ of children. ${ }^{64,104}$ Short attention span is observed in $50 \%$ of children with autism, hyperactivity in 49 and $21 \%$ according to parents and teachers, respectively. ${ }^{105}$ Children with ASD and ADHD have higher risk of suffering adverse effects from stimulant treatment than typically developing children with ADHD, showing lower rates of positive responders and less symptomatic improvement. ${ }^{106}$ To date, only clinical trials have been conducted with methylphenidate and atomoxetine in ASD. Three randomized clinical trials investigated the effects of methylphenidate in children with ASD. ${ }^{107-109}$ Three doses of medication compared to placebo were tested in a clinical trial with 66 participants with ASD in a crossover design. ${ }^{109}$ This study was classified as showing strong clinical evidence since $49 \%$ of subjects were rated to be positive responders by virtue of showing $>25 \%$ decrease in ADHD symptoms from baseline and CGI-Improvement rating of much improved or very much improved. However, $18 \%$ dropped out of the trial due to inability to tolerate the medication. ${ }^{82}$ Two other small studies with 10 and 13 children have been judged to be solidly designed, leading to the determination of a promising level of evidence for treatment with methylphenidate for hyperactivity in children with ASD. ${ }^{82}$ Doses examined were moderate in the RUPP study, based on $0.125,0.25$, and $0.5 \mathrm{mg} / \mathrm{kg}$ per dose, administered three times daily, $0.125-0.5 \mathrm{mg} / \mathrm{kg} /$ day or, $0.3-0.6 \mathrm{mg} / \mathrm{kg} /$ day. A small, randomized, controlled clinical trial was conducted with atomoxetine, a selective inhibitor of the reuptake of norepinephrine, in 16 children aged 5 to 15 years old with autism and ADHD. The treatment resulted in a response rate of $43 \%$ defined as a $25 \%$ improvement on the ABCHyperactivity subscale and CGI. A significant improvement over placebo in the hyperactivity/impulsivity subscale was also observed. ${ }^{110}$ Adverse effects were relatively mild. ${ }^{73} \mathrm{~A}$ recent European trial found evidence for superiority of atomoxetine vs. placebo on ADHD symptom measures, 
but no difference in response rates, which were low ( 21 vs. $9 \%$, respectively). ${ }^{111}$

\section{Sleep problems}

Insomnia and sleep cycle disruptions are common in ASD. Comparing the sleep patterns of 59 children with ASD aged 4 to 10 years old with 40 controls, the authors found a prevalence of $66 \%$ for moderate sleep disorders in patients with ASD. ${ }^{112}$ The literature shows a prevalence rate of sleep disorders ranging from 40 to $86 \%$ in ASD. ${ }^{113}$ These symptoms produce functional impairment and increased irritability influencing patient outcome and decreasing the family's quality of life. Many medications are used because of their sedative profile to treat sleep disorders: second-generation antipsychotics, antihistamines, benzodiazepines, alpha-agonists; however, none of them has been evaluated by a controlled clinical trial. Supplemental melatonin has shown promise in treating initial insomnia in children with autism, with several studies replicating the improvement in sleep induction. ${ }^{114}$ In addition, this agent is well tolerated by patients. A meta-analysis conducted in 2011 found 18 papers, of which five were randomized placebo controlled clinical trials that evaluated the use of 1 to $6 \mathrm{mg} /$ day of melatonin to treat sleep disorders in patients with ASD. All of them reported significant improvement in total sleep duration, number of awakenings, and reduced latency to sleep onset. ${ }^{113}$

\section{Seizures}

Although most children with autism do not have seizures, the risk of having seizures is still much higher than in typical children. Among patients with autism, 20-25\% will have seizures. A recent study ${ }^{115}$ confirmed some previous findings that $22 \%$ of participants developed epilepsy. In the majority, seizures began after 10 years of age. Generalized tonic-clonic seizures predominated $(88 \%)$. In over half (19/33), seizures occurred weekly or less frequently and in the majority of individuals (28/31) and were controlled with the use of one to two anticonvulsants. Epilepsy was associated with gender (female), intellectual disability, and poorer verbal abilities. Although the presence of epilepsy in the probands was not associated with an increased risk of epilepsy in their relatives, it was associated with the presence of a broader autism phenotype in relatives. This indicates that the familial liability to autism may be associated with the risk for epilepsy in the proband. When seizures are present, a neurological assessment is very important. The effective and safe use of many anticonvulsants requires regular needs blood drug level monitoring. It is important to note that valproic acid, the most used drug, ${ }^{116}$ can take several weeks to exert effects. However, because it may have moderate benefits in irritability and severe tantrum, valproic acid deserves consideration in the context of both symptom targets. ${ }^{117}$ Topiramate can be used in a range of seizure types and could be tried when either valproic acid or carbamazepine has failed to stop seizures, or in situations where these medications are contraindicated. Using topiramate could be an important choice given the suggestion that combined use with risperidone may increase benefits in irritability in children with ASD. Topiramate may also have beneficial effects in reducing antipsychotic-induced appetite and weight increases. ${ }^{118,119}$

\section{Conclusion}

ASD represents a major public health concern as a prevalent neurodevelopmental disorder with pronounced risk for failure of adaptation across social, educational, and psychological outcomes. Because the identification of delays and deviations of ASD is possible as early as 1824 months of age, pediatricians should strive to identify and begin intervention in children with ASD as soon as signs are manifest. Specific scales and instruments should be used to assess clinical manifestations and guide the construction and monitoring of comprehensive treatment programs. True recovery of autism is not reported in the literature, but educational, psychosocial, and language therapies, often combined with adjunctive treatments, such as drug therapy for specific symptoms, are well established for their benefits in ASD. The complex and pervasive nature of $A S D$ requires a team of multiple professionals for accurate diagnosis and clinical care.

\section{Disclosure}

James $\mathrm{T}$. McCracken receives a research grant from Seaside Therapeutics, Roche, and Otsuka, works as a consultant for Roche, and has some works with Roche and Novartis. The other authors report no conflicts of interest.

\section{References}

1 American Psychiatric Association. Manual diagnóstico e estatístico de transtornos mentais: texto revisado (DSM-IV-TR). Porto Alegre: Artmed; 2002.

2 Guthrie W, Swineford LB, Nottke C, Wetherby AM. Early diagnosis of autism spectrum disorders: stability and change in clinical diagnosis and symptom presentation. J Child Psychol Psychiatry. 2012 Oct 9. [Epub ahead of print]

3 Lotter V. Epidemiology of autistic conditions in young children. Soc Psychiatry. 1966;1:124-35.

4 Fombonne E. Epidemiology of pervasive developmental disorders. Pediatr Res. 2009;65:591-8.

5 Fombonne E. Past and future perspectives on autism epidemiology. In: Moldin SO, Rubenstein JLR, editors. Understanding autism: from basic neuroscience to treatment. Boca Raton: CRC Press; 2006. p. 25-45.

6 Elsabbagh M, Divan G, Koh YJ, Kim YS, Kauchali S, Marcin C, et al. Global prevalence of autism and other pervasive developmental disorders. Autism Res. 2012;5:160-79.

7 Fombonne E. A wrinkle in time: from early signs to a diagnosis of autism. J Am Acad Child Adolesc Psychiatry. 2009;48:463-4.

8 Autism and Developmental Disabilities Monitoring Network Surveillance Year 2006 Principal Investigators; Centers for Disease Control and Prevention (CDC). Prevalence of autism spectrum disorders - Autism and Developmental Disabilities Monitoring Network, United States, 2006. MMWR Surveill Summ. 2009;58:1-20. 
9 Paula CS, Ribeiro SH, Fombonne E, Mercadante MT. Brief report: prevalence of pervasive developmental disorder in Brazil: a pilot study. J Autism Dev Disord. 2011;41:1738-42.

10 Klin A. Autism and Asperger syndrome: an overview. Rev Bras Psiquiatr. 2006;28:s3-11.

11 Osterling JA, Dawson G, Munson J. Early recognition of 1-year-old infants with autism spectrum disorder versus mental retardation. Dev Psychopatol. 2002;14:239-51.

12 Ozonoff S, losif AM, Baguio F, Cook IC, Hill MM, Hutman T, et al. A prospective study of the emergence of early behavioral signs of autism. J Am Acad Child Adolesc Psychiatry. 2010;49:256-66.

13 Zwaigenbaum L, Bryson S, Lord C, Rogers S, Carter A, Carver L, et al. Clinical assessment and management of toddlers with suspected autism spectrum disorder: insights from studies of high-risk infants. Pediatrics. 2009;123:1383-91.

14 Rogers SJ. What are infant siblings teaching us about autism in infancy? Autism Res. 2009;2:125-37.

15 Autism and Developmental Disabilities Monitoring Network Surveillance Year 2002 Principal Investigators; Centers for Disease Control and Prevention. Prevalence of autism spectrum disorders--autism and developmental disabilities monitoring network, 14 sites, United States, 2002. MMWR Surveill Summ. 2007;56:12-28.

16 Ozonoff S. Editorial perspective: autism spectrum disorders in DSM- 5--an historical perspective and the need for change. J Child Psychol Psychiatry. 2012;53:1092-4.

17 Barbaro J, Dissanayake C. Prospective identification of autism spectrum disorders in infancy and toddlerhood using developmenta surveillance: the social attention and communication study. J Dev Behav Pediatr. 2010;31:376-85.

18 Gray KM, Tonge BJ. Screening for autism in infants and preschool children with developmental delay. Aust N Z J Psychiatry. 2005;39:378-86.

19 Robins DL, Fein D, Barton ML, Green JA. The Modified Checklist for Autism in Toddlers: an initial study investigating the early detection of autism and pervasive developmental disorders. J Autism Dev Disord. 2001;31:131-44.

20 Krug DA, Arick J, Almond P. Behavior checklist for identifying severely handicapped individuals with high levels of autistic behavior. J Child Psychol Psychiatry. 1980;21:221-9.

21 Berument SK, Rutter M, Lord C, Pickles A, Bailey A. Autism screening questionnaire: diagnostic validity. $\mathrm{Br} \mathrm{J}$ Psychiatry. 1999;175:444-51.

22 Schopler E, Reichler RJ, DeVellis RF, Daly K. Toward objective classification of childhood autism: Childhood Autism Rating Scale (CARS). J Autism Dev Disord. 1980;10:91-103.

23 Constantino JN, Davis SA, Todd RD, Schindler MK, Gross MM Brophy SL, et al. Validation of a brief quantitative measure of autistic traits: comparison of the social responsiveness scale with the autism diagnostic interview-revised. J Autism Dev Disord. 2003;33:427-33.

24 Sparrow SS, Balla DA, Cicchetti DV. Vineland Adaptive Behavior Scales. Circle Pines: American Guidance Service, Inc.; 1984.

25 Aman MG, Singh NN, Stewart AW, Field CJ. The aberrant behavior checklist: a behavior rating scale for the assessment of treatment effects. Am J Ment Defic. 1985;89,485-91.

26 Gurrieri F. Working up autism: the practical role of medical genetics. Am J Med Genet C Semin Med Genet. 2012;160C:104-10

27 Lord C, Rutter M, Dilavore P, Risi S. The autism diagnostic observation schedule: manual. Los Angeles: Western Psychological Corporation; 1999.

28 Lord C, Rutter ML, Le Couteur A. Autism diagnostic interviewrevised: a revised version of a diagnostic interview for caregivers of individuals with possible pervasive developmental disorders. J Autism Dev Disord. 1994;24:659-85.

29 Becker MM, Wagner MB, Bosa CA, Schmidt C, Longo D, Papaleo $\mathrm{C}$, et al. Translation and validation of Autism Diagnostic InterviewRevised (ADI-R) for autism diagnosis in Brazil. Arq Neuropsiquiatr 2012;70:185-90.

30 Frith U, Frith CD. Development and neurophysiology of mentalizing Philos Trans R Soc Lond B Biol Sci. 2003;358:459-73.

31 Levy SE, Mandell DS, Schultz RT. Autism. Lancet. 2009;374: 1627-38.
32 Sun J, Buys N. Early executive function deficit in preterm children and its association with neurodevelopmental disorders in childhood: a literature review. Int J Adolesc Med Health. 2012;24:291-9.

33 Lord C, Shulman C, DiLavore P. Regression and word loss in autistic spectrum disorders. J Child Psychol Psychiatry. 2004; 45:936-55.

34 Paul R, Chawarska K, Fowler C, Cicchetti D, Volkmar F. "Listen my children and you shall hear": auditory preferences in toddlers with autism spectrum disorders. J Speech Lang Hear Res 2007;50:1350-64

35 Paul R. Communication development and assessment. In: Chawarska K, Klin A, Volkmar FR, editors. Autism spectrum disorders in infants and toddlers: diagnosis, assessment and treatment. New York: Guilford Press; 2008. p. 76-103.

36 Paul R, Chawarska K, Klin A, Volkmar F. Dissociations in the development of early communication in autism spectrum disorders. In: Paul R. Language disorders from a developmental perspective: essays in honor of Robin Chapman. Hillsdale: Routledge, 2007. p. 163-95.

37 Pickett E, Pullara O, O'Grady J, Gordon B. Speech acquisition in older nonverbal individuals with autism: a review of features, methods, and prognosis. Cogn Behav Neurol. 2009;22:1-21.

38 Tager-Flusberg H, Paul R, Lord C: Language and communication in autism. In:Volkmar F, Paul R, Klin A, Cohen D, editors. Handbook of autism and pervasive developmental disorders, assessment, interventions, and policy. 3rd ed. New Jersey: John Wiley \& Sons; 2005. p. 335-64

39 Paul R, Kimberly G. Development of language and communication. In: Hollander E, Kolevzon A; Coyle, JT. Textbook of autism spectrum disorders. Arlington: American Psychiatric Publishing; 2011. p. 147-58.

40 Perissinoto J. Conhecimentos essenciais para atender bem as crianças com autismo. São José dos Campos: Pulso Editorial; 2003.

41 Tomblin B. Co-morbidity of autism and SLI: kinds, kin and complexity. Int J Lang Commun Disord. 2011;46:127-37.

42 Reisinger LM, Cornish KM, Fombonne E. Diagnostic differentiation of autism spectrum disorders and pragmatic language impairment. J Autism Dev Disord. 2011;41:1694-704.

43 McGregor KK, Berns AJ, Owen AJ, Michels SA, Duff D, Bahnsen AJ, et al. Association between syntax and lexicon among children with or without ASD and language impairment. J Autism Dev Disord. 2012;42:35-47.

44 Whitehouse AJ, Barry JG, Bishop DV. The broader phenotype of autism: a comparison with specific language impairment. J Child Psychol Psychiatry. 2007;48:822-30.

45 Bishop DVM. Overlaps between autism and language impairment: phenomimicry or shared etiology? Behav Genet. 2010;40:618-29.

46 Bishop DVM. Pragmatic language impairment: a correlate of SLI, a distinct subgroup or part of the continuum? In: Bishop DVM, Leonard LB, editors. Speech and language impairments in children: causes, characteristics, intervention ant outcome. Hove: Psychology Press; 2000. p. 99-114.

47 Pastorello LM. Síndrome de Asperger. In: Fernandes FDM, Pastorello LM, Scheuer Cl, editors. Fonoaudiologia nos distúrbios psiquiátricos da infância. São Paulo: Lovise;1996. p. 45-59.

48 Hage SRdV, Guerreiro MM. Distúrbio específico de linguagem: aspectos linguísticos e neurobiológicos. In: Fernandes FDM, Mendes BCA, Navas ALPGP, editors. Tratado de fonoaudiológia. 2nd ed. São Paulo: Roca; 2009. p. 323-9.

49 Volkmar FR, Chawarska K. Autism in infants: an update. World Psychiatry. 2008;7:19-21.

50 National Research Council. Committee on Educational Interventions for Children with Autism. Educating children with autism. Washington: National Academies Press; 2001.

51 Corcoran J. Family treatment of preschool behavior problems. Res Soc Work Pract. 2000;10:547-88.

52 Forehand R, Kotchick BA. Behavioral parent training: current challenges and potential solutions $J$ Child Fam Stud. 2002;11:377-84.

53 Wetherby AM, Woods J, Allen L, Cleary J, Dickison H, Lord C. Early indicators of autism spectrum disorders in the second year of life. $\mathrm{J}$ Autism Dev Disord. 2004;34:473-93. 
54 Wetherby AM, Woods J. Developmental approaches to treatment. In: Chawarska K, Klin A, Volkmar FR, editors. Autism spectrum disorders in infants and toddlers. New York: Guilford Press; 2008. p. 170-206

55 Wood JJ, Drahota A, Sze K, Har K, Chiu A, Langer DA. Cognitive behavioral therapy for anxiety in children with autism spectrum disorders: a randomized, controlled trial. J Child Psychol Psychiatry. 2009;50:224-34.

56 Cooper JO, Heron TE, Heward WL. Applied behavior analysis. 2nd ed. Upper Saddle River: Pearson Education; 2007.

57 Soorya LV, Carpenter LA, Romanczyk RG. Applied behavior analysis. In: Hollander E, Kolevzon A, Coyle JT, editors. Textbook of autism spectrum disorders. Arlington: American Psychiatric Publishing; 2011. p. 525-36.

58 Vismara LA, Rogers SJ. Behavioral treatments in autism spectrum disorder: what do we know? Annu Rev Clin Psychol. 2010;6:447-68.

59 Warren Z, Veenstra-VanderWeele J, Stone W, Bruzek JL, Nahmias AS, Foss-Feig $\mathrm{JH}$, et al. Agency for healthcare research and quality: Comparative effectiveness review No. 26 [Internet]. Therapies for children with autism spectrum disorders. $2011 \mathrm{Apr}$ [cited 20130 Jun 26]. http://www.ncbi.nlm.nih.gov/pubmedhealth/ PMH0015709/

60 Dawson G, Rogers S, Munson J, Smith M, Winter J, Greenson J, et al. Randomized, controlled trial of an intervention for toddlers with autism: the Early Start Denver Model. Pediatrics. 2010;125:e17-23.

61 Lovaas OI: Behavioral treatment and normal educational and intellectual functioning in young autistic children. J Consult Clin Psychol 1987;55:3-9.

62 Schopler E, Reichler RJ, Renner BR. The Childhood Autism Rating Scale (CARS): for diagnostic screening and classification of autism. New York: Irvington Publishers; 1986.

63 Reaven J, Blakely-Smith A, Culhane-Shelburne K, Hepburn S. Group cognitive behavior therapy for children with high-functioning autism spectrum disorders and anxiety: a randomized trial. J Child Psychol Psychiatry. 2012;53:410-9.

64 Aman MG, Lam KS, Collier-Crespin A. Prevalence and patterns of use of psychoactive medicines among individuals with autism in the Autism Society of Ohio. J Autism Dev Disord. 2003;33:527-34.

65 Esbensen AJ, Greenberg JS, Seltzer MM, Aman MG.A longitudinal investigation of psychotropic and non-psychotropic use among adolescents and young adults with autism spectrum disorders. J Autism Dev Disord. 2009;39:1339-49.

66 Ghaziuddin M, Tsai L, Ghaziuddin N. Comorbidity of autistic disorder in children and adolescents. Eur Child Adolesc Psychiatry. 1992;1:209-13.

67 Simonoff E, Pickles A, Charman T, Chandler S, Loucas T, Baird G. Psychiatric disorders in children with autism spectrum disorders: prevalence, comorbidity, and associated factors in a populationderived sample. J Am Acad Child Adolesc Psychiatry. 2008;47:921-9.

68 Kaplan G, McCracken JT. Psychopharmacology of autism spectrum disorders. Pediatr Clin North Am. 2012;59:175-87.

69 Lecavalier L. Behavioral and emotional problems in young people with pervasive developmental disorders: relative prevalence, effects of subject characteristics, and empirical classification. $J$ Autism Dev Disord. 2006;36:1101-4.

70 Nazzer A. Psychopharmacology of autistic spectrum disorders in children and adolescents. Pediatr Clin North Am. 2011;58:85-97.

71 Baghdadli A, Pascal C, Grisi S, Aussilloux C. Risk factors for selfinjurious behaviors among 222 young children with autistic disorders. J Intellect Disabil Res. 2003;47:622-7.

72 McCracken JT, McGough J, Shah B, Cronin P, Hong D, Aman MG, et al. Risperidone in children with autism and serious behavioral problems. N Engl J Med. 2002;347:314-21.

73 Canitano R, Scandurra V. Psychopharmacology in autism: an update. Prog Neuropsychopharmacol Biol Psychiatry. 2011;35:18-28.

74 Troost PW, Lahuis BE, Steenhuis MP, Ketelaars CE, Buitelaar JK, van Engeland $\mathrm{H}$. Long-term effects of risperidone in children with autism spectrum disorders: a placebo discontinuation study. J Am Acad Child Adolesc Psychiatry. 2005;44:1137-44.

75 Luby J, Mrakotsky C, Stalets MM, Belden A, Heffelfinger A, Williams $M$, et al. Risperidone in preschool children with autistic spectrum disorders: an investigation of safety and efficacy. J Child Adolesc Psychopharmacol. 2006;16:575-87.
76 Nagaraj R, Singhi P, Malhi P. Risperidone in children with autism: randomized, placebo-controlled, double-blind study. J Child Neurol. 2006;21:450-5.

77 Pandina GJ, Bossie CA, Youssef E, Zhu Y, Dunbar F. Risperidone improves behavioral symptoms in children with autism in a randomized, double-blind, placebo-controlled trial. J Autism Dev Disord. 2007;37:367-73.

78 Aman MG, Hollway JA, McDougle CJ, Scahill L, Tierney E, McCracken JT, et al. Cognitive effects of risperidone in children with autism and irritable behavior. J Child Adolesc Psychopharmacol. 2008;18:227-36.

79 Gencer O, Emiroglu FN, Miral S, Baykara B, Baykara A, Dirik E. Comparison of long term efficacy and safety of risperidone and haloperidol in children and adolescents with autistic disorder. An open label maintenance study. Eur Child Adolesc Psychiatry. 2008;17:217-25

80 Shea S, Turgay A, Carroll A, Schulz M, Orlik H, Smith I, et al. Risperidone in the treatment of disruptive behavioral symptoms in children with autistic and other pervasive developmental disorders. Pediatrics. 2004;114:e634-41.

81 McDougle CJ, Stigler KA, Erickson CA, Posey D. Atypical antipsychotics in children and adolescents with autistic and other pervasive developmental disorders. J Clin Psychiatry. 2008;69:15-20.

82 Siegel M, Beaulieu AA. Psychotropic medications in children with autism spectrum disorders: a systematic review and synthesis for evidence - based practice. J Autism Dev Disord. 2012;42:1592-605

83 Marcus RN, Owen R, Kamen L, Manos G, McQuade RD, Carson $\mathrm{WH}$, et al. A placebo-controlled, fixed-dose study of aripiprazole in children and adolescents with irritability associated with autistic disorder. J Am Acad Child Adolesc Psychiatry. 2009;48:1110-9.

84 Owen R, Sikich L, Marcus RN, Corey-Lisle P, Manos G, McQuade $\mathrm{RD}$, et al. Aripiprazole in the treatment of irritability in children and adolescents with autistic disorder. Pediatrics. 2009;124:1533-40.

85 Anderson LT, Campbell M, Adams P, Small AM, Perry R, Shell J. The effects of haloperidol on discrimination learning and behavioral symptoms in autistic children. J Autism Dev Disord. 1989;19: 227-39.

86 Anderson LT, Campbell M, Grega DM, Perry R, Small AM, Green WH. Haloperidol in infantile autism: effects on learning and behavioral symptoms. Am J Psychiatry. 1984;141:1195-202.

87 Miral S, Gencer O, Inal-Emiroglu FN, Baykara B, Baykara A, Dirik $E$. Risperidone versus haloperidol in children and adolescents with AD: a randomized, controlled, double-blind trial. Eur Child Adolesc Psychiatry. 2008;17:1-8.

88 Horrigan JP, Barnhill LJ, Courvoisie HE. Olanzapine in PDD. J Am Acad Child Adolesc Psychiatry. 1997;36:1166-7.

89 Heimann SW. High-dose olanzapine in an adolescent. J Am Acad Child Adolesc Psychiatry. 1999;38:496-8.

90 Potenza MN, Holmes JP, Kanes SJ, McDougle CJ. Olanzapine treatment of children, adolescents, and adults with pervasive developmental disorders: an open-label pilot study. J Clin Psychopharmacol. 1999;19:37-44.

91 Malone RP, Cater J, Sheikh RM, Choudhury MS, Delaney MA. Olanzapine versus haloperidol in children with autistic disorder: an open pilot study. J Am Acad Child Adolesc Psychiatry. 2001;40:887-94

92 Bonanno DG, Davydov L, Botts SR. Olanzapine-induced diabetes mellitus. Ann Pharmacother. 2001;35:563-5.

93 Malone RP, Delaney MA, Hyman SB, Cater JR. Ziprasidone in adolescents with autism: an open-label pilot study. J Child Adolesc Psychopharmacol. 2007;17:779-90.

94 Cohen SA, Fitzgerald BJ, Khan SR, Khan A. The effect of a switch toziprasidone in an adult population with autistic disorder: chart review of naturalistic, open-label treatment. J Clin Psychiatry. 2004;65:110-3.

95 McDougle CJ, Kem DL, Posey DJ. Case series: use of ziprasidone for maladaptive symptoms in youths with autism. J Am Acad Child Adolesc Psychiatry. 2002;41:921-7.

96 Martin A, Koenig K, Scahill L, Bregman J. Open-label quetiapineinthe treatment of children and adolescents with autistic disorder. J Child Adolesc Psychopharmacol. 1999;9:99-107.

97 Chen NC, Bedair HS, McKay B, Bowers MB Jr, Mazure C. Clozapine in the treatment of aggression in an adolescent with autistic disorder. J Clin Psychiatry. 2001;62:479-80. 
98 Kolevzon A, Mathewson KA, Hollander E. Selective serotonin reuptake inhibitors in autism: a review of efficacy and tolerability. $J$ Clin Psychiatry. 2006;67:407-14.

99 Soorya L, Kiarashi J, Hollander E. Psychopharmacologic interventions for repetitive behaviors in autism spectrum disorders. Child Adolesc Psychiatr Clin N Am. 2008;17:753-71.

100 Hollander E, Phillips A, Chaplin W, Zagursky K, Novotny S, Wasseman S, et al. A placebo controlled crossover trial of liquid fluoxetine on repetitive behaviors in childhood and adolescent autism. Neurophycopharmacology. 2005;30:582-9.

101 King BH, Hollander E, Sikich L, McCracken JT, Scahill L, Bregman JD, et al. Lack of efficacy of citalopram in children with autism spectrum disorders and high levels of repetitive behavior: citalopram ineffective in children with autism. Arch Gen Psychiatry. 2009;66;583-90.

102 McDougle CJ, Naylor ST, Cohen DJ, Volkmar FR, Heninger GR, Price LH. A double-blind, placebo-controlled study of fluvoxamine in adults with autistic disorder. Arch Gen Psychiatry. 1996:53:1001-8.

103 Hollander E, Soorya L, Chaplin W, Anagnostou E, Taylor BP, Ferretti CJ, et al. A double-blind placebo-controlled trial of fluoxetine for repetitive behaviors and global severity in adult autism spectrum disorders. Am J Psychiatry. 2012;169:292-9.

104 Goldstein S, Schewebach AJ. The comorbidity of pervasive developmental disorder and attention disorder: results of a retrospective chart review. J Autism Dev Disord. 2004;34:329-39.

105 Aman MG, Farmer CA, Hollway J, Arnold LE. Treatment of inattention, overactivity, and impulsiveness in autism spectrum disorders. Child Adolesc Psychiatr Clin N Am. 2008;17:713-38.

106 Nikolov R, Jonker J, Scahill L. Autistic disorder: current psychopharmacological treatments and areas of interest for future developments. Rev Bras Psiquiatr. 2006;28:s39-46.

107 Quintana H, Birmaher B, Stedge D, Lennon S, Freed J, Bridge J, et al. Use of methylphenidate in the treatment of children with autistic disorder. J Autism Dev Disord. 1995;25:283-94.

108 Handen BL, Johnson CR, Lubetsky M. Efficacy of methylphenidate among children with autism and symptoms of attention-deficit hyperactivity disorder. J Autism Dev Disord. 2000;30:245-55.

109 Research Units on Pediatric Psychopharmacology Autism Network. Randomized, controlled, crossover trial of methylphenidate in pervasive developmental disorders with hyperactivity. Arch Gen Psychiatry. 2005;62:1266-74.

110 Eugene Arnold L; Children with Hyperactivity \& ASD Research Treatment Study (CHARTS) Consortium. Atomoxetine reduces ADHD symptoms in children with autism spectrum disorder. Evid Based Ment Health. 2012;15:96.

111 Harfterkamp M, van de Loo-Neus G, Minderaa RB, van der Gaag RJ, Escobar R, Schacht A, et al. A randomized double-blind study of atomoxetine versus placebo for attention-deficit/hyperactivity disorder symptoms in children with autism spectrum disorder. J Am Acad Child Adolesc Psychiatry. 2012;51:733-41.

112 Souders MC, Mason TB, Valladares O, Bucan M, Levy SE, Mandell DS, et al. Sleep behaviors and sleep quality in children with autism spectrum disorders. Sleep. 2009;32:1566-78.

113 Rossignol DA, Frye RE. Melatonin in autism spectrum disorders: a systematic review and meta-analysis. Dev Med Child Neurol. 2011;53:783-92

114 Malow BA, Byars K, Johnson K, Weiss S, Bernal P, Goldman SE, et al. A practice pathway for the identification, evaluation, and management of insomnia in children and adolescents with autism spectrum disorders. Pediatrics. 2012;130:S106-24.

115 Bolton PF, Carcani-Rathwell I, Hutton J, Goode S, Howlin P, Rutter M. Epilepsy in autism: features and correlates. Br J Psychiatry. 2011;198:289-94.

116 Frye RE, Sreenivasula S, Adams JB. Traditional and non traditional treatments for autism spectrum disorder with seizures: an on-line survey. BMC Pediatr. 2011;11:37.

117 Hollander E, Chaplin W, Soorya L, Wasserman S, Novotny S, Rusoff J, et al. Divalproex sodium vs placebo for the treatment of irritability in children and adolescents with autism spectrum disorders. Neuropsychopharmacology. 2010;35:990-8.

118 Rezaei V, Mohammadi MR, Ghanizadeh A, Sahraian A, Tabrizi M, Rezazadeh SA, et al. Double-blind, placebo-controlled trial of risperidone plus topiramate in children with autistic disorder. Prog Neuropsychopharmacol Biol Psychiatry. 2010;34:1269-72.

119 Fiedorowicz JG, Miller DD, Bishop JR, Calarge CA, Ellingrod VL, Haynes WG. Systematic review and meta-analysis of pharmacological interventions for weight gain from antipsychotics and mood stabilizers. Curr Psychiatry Rev. 2012;8:25-36. 